\title{
Why do Dolphins Play?
}

\author{
Stan A. Kuczaj ${ }^{1 *}$ and Holli C. Eskelinen ${ }^{2}$ \\ ${ }^{1}$ University of Southern Mississippi \\ ${ }^{2}$ Dolphins Plus \\ *Corresponding author (Email: s.kuczaj@usm.edu)
}

Citation - Kuczaj, S. A., \& Eskelinen, H. C. (2014). Why do dolphins play? Animal Behavior and Cognition, 1(2), 113-127. doi: 10.12966/abc.05.03.2014

\begin{abstract}
Play is an important aspect of dolphin life, perhaps even an essential one. Play provides opportunities for dolphin calves to practice and perfect locomotor skills, including those involved in foraging and mating strategies and behaviors. Play also allows dolphin calves to learn important social skills and acquire information about the characteristics and predispositions of members of their social group, particularly their peers. In addition to helping dolphin calves learn how to behave, play also provides valuable opportunities for them to learn how to think. The ability to create and control play contexts enables dolphins to create novel experiences for themselves and their playmates under relatively safe conditions. The behavioral variability and individual creativity that characterize dolphin play yield ample opportunities for individual cognitive development as well as social learning, and sometimes result in innovations that are reproduced by other members of the group. Although adults sometimes produce innovative play, calves are the primary source of such innovations. Calves are also more likely to imitate novel play behaviors than are adults, and so calves contribute significantly to both the creation and transmission of novel play behaviors within a group. Not unexpectedly, then, the complexity of dolphin play increases with the involvement of peers. As a result, the opportunity to observe and/or interact with other dolphin calves enhances the effects of play on the acquisition and maintenance of flexible problem solving skills, the emergence and strengthening of social and communicative competencies, and the establishment of social relationships. It seems that play may have evolved to help young dolphins learn to adapt to novel situations in both their physical and social worlds, the beneficial result being a set of abilities that increases the likelihood that an individual survives and reproduces.
\end{abstract}

Keywords - Dolphin play, Cognitive development, Social development, Moderately discrepant events, Flexible problem solving

Play is notoriously difficult to define, regardless of the species that is playing (Burghardt, 2005; Kuczaj \& Horback, 2013). A determination of the precise reasons why animals play has also proven evasive, perhaps because play serves a myriad of functions (see Bekoff \& Allen, 1998; Burghardt, 2005; Fagen, 1981; Groos \& Baldwin, 1898; Kuczaj \& Makecha, 2008; Pelligrini, 2011; Paulos, Trone, \& Kuczaj, 2010; Špinka, Newberry, \& Bekoff, 2001). Despite the difficulty of defining and explaining play to everyone's satisfaction, it is usually easy to discriminate play and non-play behavior, and observations and anecdotes concerning animal play abound in the literature.

Although play has been observed in many cetacean species (see Paulos et al., 2010, for a review and summary), our focus in this paper will be on delphinid species, especially bottlenose dolphins (Tursiops truncatus). The reason for this focus is simple. We know much more about play in dolphins 
than we do about play in other cetaceans. Dolphins of all ages play, although play is more common in young dolphins than in adult dolphins (Paulos et al., 2010). Does the fact that young dolphins play more than older dolphins reflect developmental differences in the functions of play? Or do young dolphins simply have more time and/or energy to play? In this paper, we examine possible reasons for developmental differences in play among dolphins and for the prevalence of play in dolphins in general. We conclude that play is an essential characteristic of dolphin life and that it serves a variety of functions for dolphins. Some of these functions change with maturation while others remain constant throughout the lifespan. But age is not the only factor that influences play in dolphins. Individual differences also affect the amount and the types of play in which a dolphin engages. Consequently, it is necessary to consider both ontogeny and personality in explanations of dolphin play.

\section{What is dolphin play?}

Dolphin play is multifaceted, and need not involve objects. Locomotor play occurs when dolphins repeat or vary their own behavior (Paulos et al., 2010). Although aerial behaviors such as leaps, spins, and breaches serve foraging and communicative functions (Lusseau, 2006; Würsig \& Würsig, 1980), they also occur in playful contexts in the wild (Bel'kovich, Ivanova, Kozarovitsky, Novikova, \& Kharitonov, 1991; Würsig \& Würsig, 1979, 1980) and in captivity (Trone, Kuczaj, \& Solangi, 2005).

Dolphins do play with objects. In fact, as shown in Table 1 , dolphins will play with virtually anything. Dolphins maintained in captivity play with objects they are given (e.g., balls, buoys, and ropes), objects they find (e.g., feathers, hats, and wallets), objects they create (bubbles and bubble rings), animals they capture to use as toys (e.g., birds, fish, eels), prey items that are played with prior to being consumed (fish and eels), and animals that are unwittingly and unwillingly treated as play objects (e.g., sea stars, sea turtles, sharks). Humans rarely provide wild dolphins with toys, but wild dolphins will play with objects that they happen upon (e.g., plastic, sea weed), objects they produce (bubbles), animals that will not be consumed (birds, jelly fish, sperm whales), and prey animals that may or may not be eaten after the play bout is completed (fish).

Table 1

Examples of Objects used in Play by Various Species in Captivity and in the Wild

\begin{tabular}{lll}
\hline \multicolumn{1}{c}{ Species } & \multicolumn{1}{c}{ Wild } & \multicolumn{1}{c}{ Captive } \\
\hline $\begin{array}{l}\text { Amazon River dolphin } \\
\text { (Ina geoffrensis) }\end{array}$ & fish, seaweed, wood & bubbles, pool cleaning equipment \\
Atlantic spotted dolphin (Stenella frontalis) & $\begin{array}{l}\text { bottlenose dolphin, bubbles, sea } \\
\text { turtle, seaweed }\end{array}$ & \\
& $\begin{array}{l}\text { bird, cape fur seal, fish, harbor } \\
\text { porpoise, humpback whale, } \\
\text { Bottlenose dolphin } \\
\text { (Tursiops truncatus) }\end{array}$ & $\begin{array}{l}\text { balls, bird, bubbles, buckets, buoys, } \\
\text { coins, eel, feather, fish, gauze, hoops, } \\
\text { net, pool cleaning equipment, plastic } \\
\text { bag, ropes, rubber objects, sea lion, }\end{array}$ \\
& & $\begin{array}{l}\text { seaweed, scarves, shark, skate/ray, } \\
\text { sunglasses, tape, wallet, water hose, } \\
\text { water spraying/spitting, wood }\end{array}$
\end{tabular}


Table 1 (cont.)

\begin{abstract}
Common dolphin
(Delphinus delphis)
\end{abstract}

Estuarine dolphin

(Sotalia fluviatilis)

Dusky dolphin

(Lagenorhynchus obscrus)

False killer whale

(Pseudorca crassidens)

Hawaiian spinner dolphin (Stenella longirostris)

Harbor porpoise

(Phocoena phocoena)

Hector's dolphin (Cephalorhynchus hectori)

Indo-Pacific dolphin

(Sousa chinensis)

Killer whale

(Orcinus orca)

Long-beaked common dolphin

(Delphinus capensis)

Pacific white-sided dolphin

(Lagenorhynchus obliquidens)

Pantropical spotted dolphin

(Stenella attenuata)

Pilot whale

(Globicephala)

Rough-toothed dolphin

(Steno bredanensis)

Spinner dolphin

(Stenella longirostris)

Striped dolphin

(Stenella coeruleoalba) sea turtle

fish

seaweed, plastic bags, wood

bird, seaweed, South American sea

lion, Southern right whale

ball

Seaweed

towel

sea star

Seaweed

sea turtle

birds, sea turtle

ball, birds

sea turtle

sea turtle

feather

sea turtle

bird, sea turtle

rubber tire

artificial swim leg, fish, jellyfish, buoy, hoop plastic bag, puffer fish, sea turtle, seaweed, sperm whale

sea turtle

sea turtle 


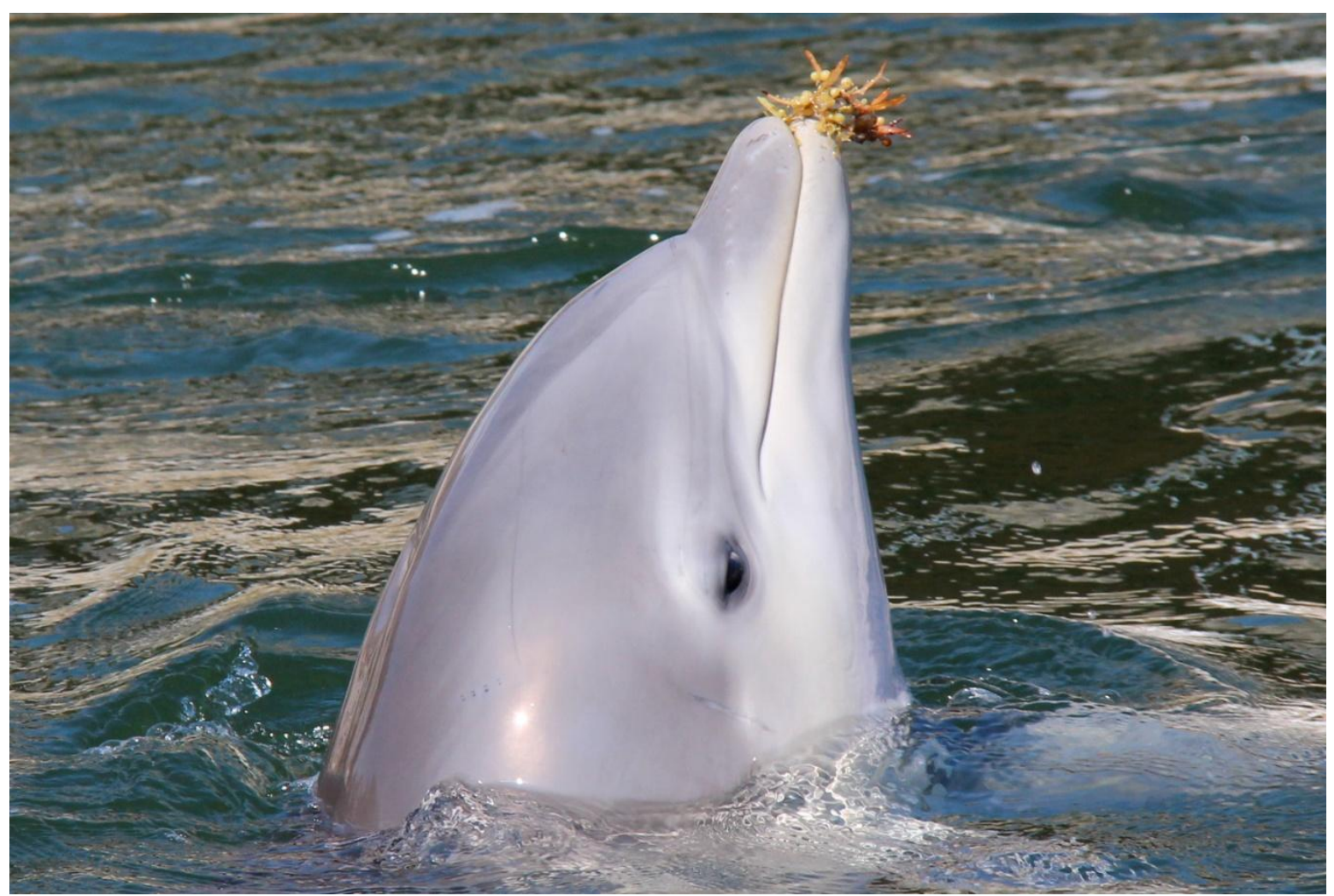

Figure 1. A five-month-old dolphin calf plays with a piece of sargassum (Sargassum muticum).

Dolphins also play with one another. In a longitudinal study of three dolphin calves, the relative frequency and the complexity of social play were found to increase throughout the first year of life (Mackey, Makecha, \& Kuczaj, 2014). This pattern has also been observed in other species. For example, kittens (Felis catus: West, 1974), Cuvier's gazelles (Gazella cuvieri: Gomendio, 1988), and hyenas (Hyaenidae: Drea, Hawk, \& Glickman, 1996) all tend to engage in more interactive social play as they mature. Mackey et al. (2014) found that the mother was typically a dolphin calf's first social play partner. However, calf social play became increasingly likely to involve another calf rather than the mother shortly as calves matured. Calves also became more likely to seek out others for social play bouts with increasing age and so were more likely to initiate social play interactions as they matured and less likely to be solicited by other dolphins for a play bout. Young calves preferred to play with calves of similar ages, but became more likely to play with older calves as they themselves grew older. Thus, a fourmonth-old calf might prefer to interact with other calves close to its age, but the same calf at 10 months of age might be equally likely to play with a 24 month old as with other 10 month olds. Playing with older animals and attempting to mimic the older calves' more advanced play behaviors are aspects of a more general tendency for dolphin calves to increase the challenging aspects of their play as they mature (Kuczaj, Makecha, Trone, Paulos, \& Ramos, 2006).

So far, we have provided a brief overview of dolphin play in order to provide a general sense of the characteristics of such play. More in depth considerations of dolphin play can be found in Kuczaj et al. (2006), Kuczaj \& Horback, 2013, Mackey et al. (2014), and Paulos et al. (2010), but our quick dip into the pool of dolphin play is sufficient for us to turn to the main purpose of this paper - attempting to explain why dolphins play. 


\section{Why do dolphins play?}

"Why do dolphins play?" seems like a simple question, but there is no simple answer. Dolphins play for a number of reasons, and an explanation of dolphin play must take into account all of these purposes.

Dolphins play because they are young. Adult dolphins play, so it is erroneous to conclude that only young dolphins play. However, it is true that dolphin calves and juveniles play more than adult dolphins (Paulos et al., 2010; Würsig \& Würsig, 1979). Dolphins are similar to other species in this regard (Burghardt, 2005; Pellegrini, 2011; Fagen, 1981). Although the negative correlation between age and play does not explain why dolphins (young or old) play, it is nonetheless an important aspect of dolphin play.

Given that young animals are more likely to play than are older animals, many theorists have suggested that play is developmentally significant (Bjorklund \& Pelligrini, 2010; Erikson, 1977; Kuczaj et al., 2006; Kuczaj \& Walker, 2012; Martin \& Caro, 1985; Pellegrini, 2011; Piaget, 1962; Vygotsky, 1978). For example, play may help the young of a species to develop important social skills and knowledge (Bekoff \& Byers, 1981; Connoly \& Doyle, 1984; Pellis \& Pellis, 2007; Piaget, 1962; Vygotsky, 1978). Determining one's place in a social network, learning to identify and interact with members of one's group, and discovering how to regulate one's own emotions and interpret the emotional states of others are all important developmental accomplishments for social species, and play may benefit the acquisition of these social skills (Bekoff \& Byers, 1981; Fagen, 1981; Gottman, 1986; Kuczaj \& Horback, 2013; Martin \& Caro, 1985; Pellis \& Pellis, 2009).

Dolphins play because playing is fun and/or pleasurable. Early explanations of play emphasized the pleasurable nature of play (Buhler, 1935; Buytendijk, 1933; Gilmore, 1966), the general idea being that playing is fun. More recently, one of the leading scholars of animal play included the "pursuit of pleasure" in his list of play functions (Burghardt, 2005). Animals, including dolphins, play because doing so is fun. But even if dolphins are motivated to play because such activities are pleasurable, the functions that play serves go beyond the simple pursuit of fun. Play may have evolved to serve a wide range of functions, the pleasure that is associated with play insuring that animals (especially young animals) do the homework that nature has assigned them by playing.

Although pleasure and play are intimately linked, it is not the case that play is always fun (Burghardt, 2005). The veneer of pleasure that accompanies play is sometimes thin, and may vanish altogether. A pleasurable play experience can quickly change into an experience that produces more negative emotions (Burghardt, 2005). The following example was provided by Kuczaj and Horback (2013):

We witnessed an example of solitary play changing from fun to surprise when a young dolphin playing with a large crab had the tables turned on him by the crab. The dolphin was grabbing the crab with its mouth, carrying the crab for a distance, releasing the crab, and then catching the crab before the crab settled to the bottom. This behavior continued until the overly confident dolphin nonchalantly mouthed the crab and received a pinch on its tongue for its efforts. This was immediately followed by a dolphin yelp and the dolphin hurrying back to its mother. What had started out as a pleasurable experience for the dolphin (but perhaps not for the crab) became a painful one, at which time the play bout ended ( $\mathrm{p}$. 96).

Although the young dolphin in the above example may not have realized it was taking a risk with the crab, dolphins do sometimes play in ways that suggest they are testing the boundaries of safety. 
Deakos, Branstetter, Mazzuca, Fertl, and Mobley (2010) observed dolphins playing with humpback whales (Megaptera novaeangliae) by swimming above a whale's head until the whale lifted its head and a dolphin out of the water, resulting in the dolphin sliding down the whale's head into the water. This behavior was repeated, suggesting that it was a form of play for the dolphins and perhaps even the whales. This is certainly a risky play activity for the dolphins, and it may be this unusual risk that motivated the behavior.

Similarly, we have observed dolphins housed in pools with ledges balancing on ledges that separate pools or are the top of an exterior wall. This behavior is not encouraged by oceanarium staff since dolphins that balance themselves on a thin ledge on an exterior wall are at risk of falling to the floor of the outside area surrounding the pool, a fall that could injure the dolphin. We suspect that the challenge of balancing oneself on a ledge is stimulating for the dolphins that engage in the balancing game, a behavior that is certainly not part of their natural repertoire. However, just as playing with a humpback whale places a dolphin at risk, dolphins that choose to balance on ledges risk injury if they lose their balance and fall outside of their enclosure.

Social play also has the potential to become dangerous. Social play fights are common among young animals, but play fights become more likely to escalate into actual fights with increasing age (Burghardt, 2005; Kuczaj \& Horback, 2013; Pellis \& Pellis, 1996; Power, 2000; Sommer \& MendozaGranados, 1995). The sometimes sudden transition from play to aggression may reflect the multitude of emotions that accompany play (Burghardt, 2005). Play provides a safe means for young animals to experience a variety of emotions (Burghardt, 2005; Kuczaj \& Horback, 2013; Singer \& Singer, 1990; Sutton-Smith, 2003, 2011), but emotional changes during a play bout can sometimes result in a playful context being transformed into a more serious and sometimes dangerous one. Although we do not know exactly how dolphins interpret the emotions of other dolphins, the nature of their social interactions suggest that they are able to do so (Kuczaj, Highfill, Makecha, \& Byerly, 2013). Learning more about the manner in which young dolphins develop the skills necessary to interpret the emotions of others will increase our understanding of both dolphin play and dolphin life in general.

Dolphins play to practice important behaviors. The notion that play provides opportunities for animals to practice important skills is prevalent in the play literature (see Burghardt, 2005; Byers \& Walker, 1995; Fagen, 1981; Kuczaj \& Horback, 2013; Kuczaj \& Makecha, 2008) for more detailed considerations of this hypothesis). For example, the exercise involved in locomotor play helps to strengthen and condition a young animal's developing body and so improves its overall physical condition. Locomotor play also provides opportunities for animals to practice behaviors such as creeping, sprinting and leaping, such play helping young prey animals develop essential anti-predator escape behaviors and young predator animals to perfect their hunting skills (Byers \& Walker, 1995; Caro, 1995; Power, 2000; Spinka et al., 2001).

One form of solitary play that has rarely been studied in non-human animals concerns communication systems. Young human children play with sounds, words, and word combinations as they acquire their first language (Kuczaj, 1982, 1983; Weir, 1962), and it is possible that young dolphins might play with sounds as they develop their acoustic repertoire (Kuczaj, in press; Kuczaj \& Makecha, 2008). Dolphin calves must learn to produce the sounds that will comprise the acoustic part of their communicative system, and experience is an important component of this process (Fripp et al., 2005). We strongly suspect that calves play with sounds and sound combinations as they consolidate the whistles, barks, squawks, burst pulses and other sounds that they will use to communicate. They may even play with echolocation clicks as they master this essential sensory system.

Social play also provides opportunities for young animals to practice behaviors that could prove useful in later life. Physical play with conspecifics can facilitate the acquisition of behaviors used in foraging, hunting, fleeing, courtship and mating, and fighting (Vieira \& Sartorio, 2002). So even though physical social play typically involves members of the same species, the behaviors that are practiced in such play can influence interactions with members of other species as well as members of their own social group. 
It is important to remember that the practice that occurs during play is not forced repetition, but instead spontaneous behavior that is typically quite exuberant. As Kuczaj and Horback (2013) noted,

The practice that occurs during play is neither mundane nor boring. Instead, the play context provides an intrinsically reinforcing scenario in which children and young animals enjoy the activities in which they are engaging, the result being a much more efficient learning session than one in which youngsters' attention is being directed by others (p. 105).

As noted earlier, play can be dangerous. Animals must be aware of potential dangers in order to avoid being injured or killed while practicing physical skills or play jousting with another. They must also be sensitive to the emotional state of their play partner. Otherwise, a play fight could quickly transform itself into something more serious. But the risk itself may be motivating in some cases, such as dolphins balancing on a ledge or a young animal seeing just how far it can go in a play fight with an older animal before the consequences become dangerous. We suspect that personality plays a role in this, with some animals more likely to be reinforced by risk-taking than others.

Dolphins play because other dolphins are playing. Dolphin play is contagious. An object becomes more interesting to dolphins if another dolphin plays with it. Dolphins of all ages become interested in the objects with which other dolphins are interacting, even if the objects had been ignored by these same dolphins prior to the play activity or are commonplace in their environment. Stimulus enhancement of this sort is a form of observational learning and explanations of why dolphins' interest in objects is piqued by other dolphin's play will likely involve considerations of social status, personality, and social learning.

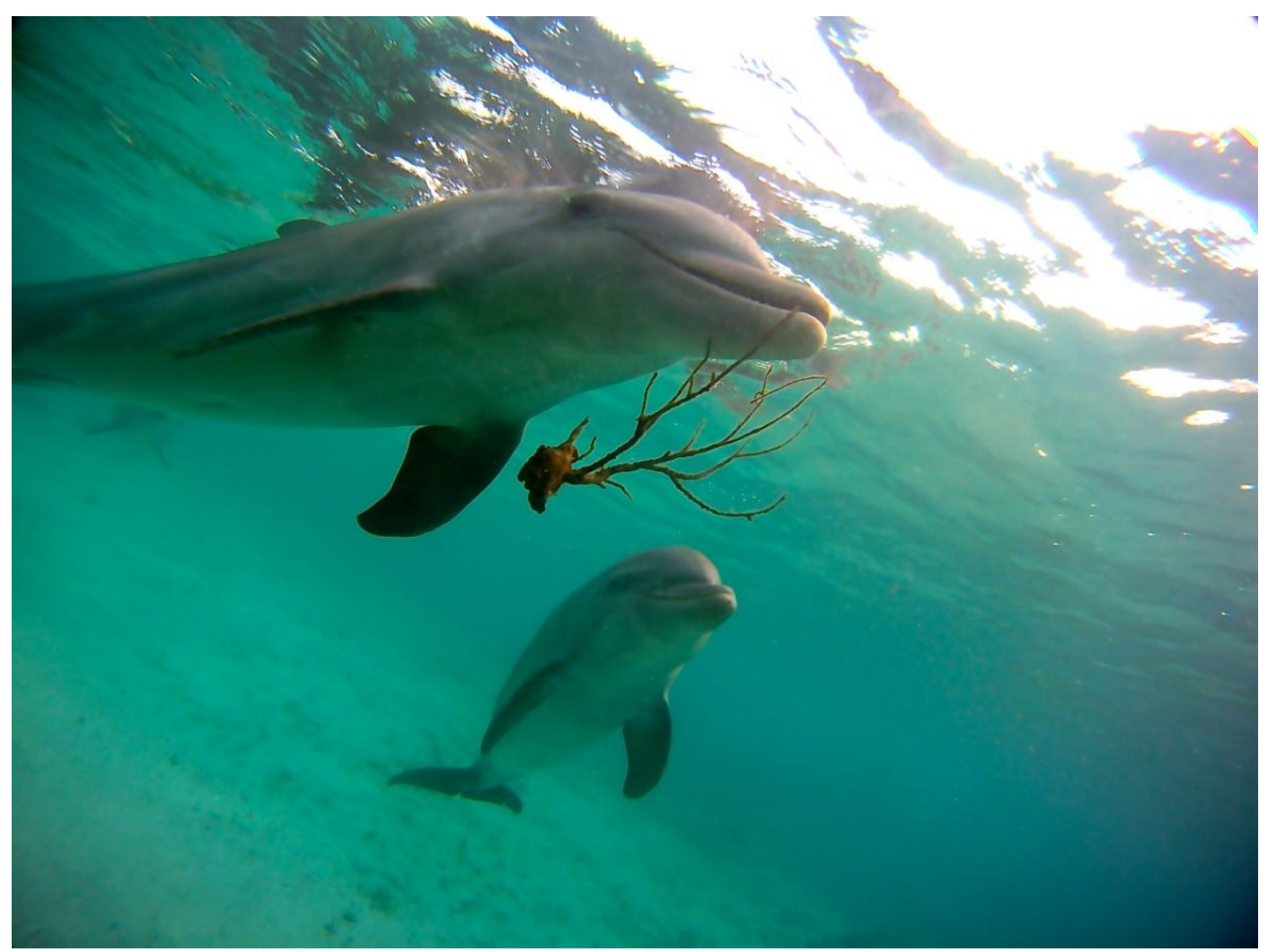

Figure 2. A young dolphin plays with an object it found on the seabed while another dolphin watches. 
We do know that the play of dolphin calves is strongly influenced by other calves. Calves produce play behaviors earlier in life if they have the opportunity to observe other (typically older) calves engaging in the same behaviors (Kuczaj et al., 2006). Calves are also more likely to imitate novel play behaviors produced by other calves than by those produced by adults, including their mothers (Kuczaj et al., 2006). This preference for some models over others demonstrates that not all models are equally interesting. Instead, some models are more salient than others, the saliency of a model reflecting the characteristics of the model, the characteristics of the observer, and the context in which the modeled behavior occurs.

The important point is that dolphin calves are neither indiscriminate observers of other dolphins' behaviors nor mindless mimics of behaviors they witness. Their social learning is selective, and they choose who to observe and who to imitate depending on the behavioral context (Kuczaj, Yeater, \& Higfill, 2012). Learning to forage is a critical survival skill for wild dolphins, and observing and mimicking the foraging strategies of its mother increases a calf's chances of surviving (Addink \& Smeenk, 2001; Bender, Herzing, \& Bjorklund, 2009; Holmes \& Neil, 2012; Krützen, Mann, Heithaus, Connor, Bejder, \& Sherwin, 2005; Lodi \& Hetzel, 1999; Smeenk, Addink, \& Richards, 1995). However, the play context is different. Other calves that are playing are much more interesting than the calf's mother, and so calves are more likely to watch and imitate the play behaviors of other calves. Of course, this depends on both a calf's personality and the mother's style (if the mother will let them play with others; see Hill, Kuczaj, Greer, \& Solangi, 2007, for a discussion of maternal styles in dolphins). Berger (1980) found that bighorn sheep (Ovis canadensis) lambs that rarely left their mothers engaged in contact play with other lambs at later ages than did lambs that were allowed to frolic with other youngsters at an earlier age, and we suspect that the same patterns occur for dolphin calves. The extent to which a calf's independent behavior (or its lack) reflects its personality or its mother's maternal style likely varies from mother-calf pair to mother-calf pair.

Exploratory play appears to facilitate the imitation of novel behavior (Miklósi, 1999), and so observing other dolphins playing may encourage calves to attempt to reproduce the play behaviors they witness. Perhaps they are more likely to mimic other calves because calves are more similar to one another in body size than are any calf and adult, this similarity making it easier to interpret, remember, and reproduce the observed behavior (Kuczaj et al., 2006; Yando, Seitz, \& Zigler, 1978). The tendency to observe and mimic other calves' play behaviors may have also evolved as a means to the increase the social cohesiveness of a calf group (Kuczaj et al., 2006). Adult humans that are imitated are more likely to be helpful and generous to others (not just the mimicker), suggesting that imitation may increase prosocial behavior in a group (van Baaren, Holland, Kawakami, \& Knippenberg, 2004). This led Kuczaj and colleagues (Kuczaj et al., 2006) to speculate that dolphin calves may be predisposed to observe and mimic other calves as a means to facilitate and maintain positive social interactions within the peer group.

Why are some calves more preferred models than others? Older calves are frequently imitated by younger calves because the older calves produce behaviors that the young animals do not know, the novelty of witnessing another dolphin almost its own size producing novel (to the young dolphin) behaviors apparently increasing the saliency of the behaviors (Chirigin, 1987; Kuczaj et al., 2006; Mackey et al., 2014). This supposition is supported by the finding that dolphin calves produce more complex play behaviors at an earlier age if there are older calves in their social groups (Kuczaj et al., 2006). Being able to observe older calves appears to motivate younger calves to attempt play behaviors at an earlier age than they would otherwise, and also seems to increase the overall complexity of the young calves' play behavior repertoire. This pattern is not found in all species. For example, infant sable antelopes (Hippotragus niger) prefer same age play partners (Thompson, 1996).

Although older calves are more likely to be mimicked than are same-age or younger peers, age is not the sole factor that determines the saliency of a model. Dolphins have distinct individual personalities (Highfill \& Kuczaj, 2007, 2010; Kuczaj, Highfill \& Byerly, 2012), and a dolphin's personality influences the extent to which other dolphins attend to and attempt to reproduce its behavior (Kuczaj, Yeater \& Highfill, 2012). The bolder and more curious dolphins are more likely to be observed and mimicked than are the timid and cautious dolphins. For example, when dolphins first encountered a swimmer with an 
artificial swim leg, the bolder calves and juveniles were the first to examine the leg, swimming close to it, orienting and echolocating on it (Kuczaj et al., 2012). In contrast, the more cautious calves remained a short distance behind the bolder animals, always kept the bold animal between themselves and the novel object, and watched the bold calf's behavior intently. The bold animals quickly became more adventurous, gently mouthing and sometimes even lightly pulling on the leg. The cautious dolphins did not interact with the leg until they had witnessed the bolder animals' interactions with it, and the cautious animals' interactions were invariably attempts to replicate what they had observed the bolder animals doing. These and similar results demonstrate that dolphin social learning is selective, and is influenced by a number of factors: behavioral context, novelty of behavior and/or model, the social significance of the model, and personality (Kuczaj et al., 2012).

As noted above, young dolphins may acquire important social skills during play and may challenge themselves by playing with more competent peers or even adults. During social play, an older and/or more adept animal may opt to handicap itself to both encourage playful interactions with a younger animal and to avoid injuring the youngster. If the dolphins are playing a social game, such as playfighting or play-mating, the more dominant animal may play a subordinate role, such role reversals being rarely observed outside of the play context.

A young or subordinate animal that wishes to play with a stronger or more dominate conspecific must be certain that the other wants to play. Part of this assessment rests on an ability to correctly ascertain the emotional state of the other dolphin (Kuczaj \& Horback, 2013). This assessment is simplified if there is a play signal that is used to signal willingness to play.

Social play is only possible if the players communicate with one another in order to establish common "play frames" (Bateson, 1955, 1972; Sutton-Smith, 1980). Play signals are used to communicate playful intent, helping to insure that behaviors that occur in a playful context are not interpreted as seriously as they would be in a non-play context (Bateson, 1955, 1972). Such signals have been discovered in numerous species (Burghardt, 2005; Kuczaj \& Horback, 2013; Palagi, 2009; Pellis \& Pellis, 2011), and it is possible that dolphins also use play signals.

One acoustic play signal has been observed in captive dolphins, and occurs during play-fight contexts (Blomqvist, Mello, \& Amundin, 2005). Play-fighting is a common context in which play signals are observed, most likely because such play fights can escalate into real fights and it is important to monitor the emotional state of one's opponents in order to maintain and even repair the playful context (Kuczaj \& Horback, 2013). Another possible dolphin play signal was reported by Kuczaj and Makecha (2008). They observed dolphin calves remaining stationary on the surface of the water, a behavior that usually resulted in another young dolphin approaching the stationary animal and pushing it sideways through the water. Kuczaj and Makecha proposed that the stationary floating behavior signaled "willingness to be pushed" to other calves. This behavior was only produced during play contexts and always resulted in the floating dolphin either being ignored by other dolphins or being pushed sideways along the surface of the water. If the floating dolphin was pushed, it sometimes solicited another push by assuming the surface floating position again. But in some cases, two dolphins took turns, alternating the roles of "pusher" and "pushee." Cooperative play requires communication, and Kuczaj and Makecha suggested that the surface floating behavior was an essential play signal for this dolphin game.

Play signals have not been observed in wild dolphins, but it seems likely that similar signals exist in wild populations. Young dolphins engage in play fights in the wild as well as in captivity, and the need to communicate playful intent is important in both contexts. Adult rough-toothed (Steno bredanensis) dolphins play with younger animals (Kuczaj \& Highfill, 2005), and it is possible that adults use a play signal to encourage the younger animals' participation.

Specific play signals are not used in all forms of social play, and so playful intent must be communicated in other ways. If a species has evolved the ability to reliably interpret the emotional states of others, the positive emotions associated with play may be the only information that is needed to communicate a play context (Kuczaj \& Horback, 2013). But dolphins may also use other cues such as the overall social context to hazard guesses about other's behavioral intentions. Chimpanzees (Pan troglodytes) interpret the overall context as well as facial expressions in emotional scenarios (Kano \& 
Tomonaga, 2010), and Kuczaj and Horback (2013) suggested that animals might also use a variety of cues to assess playfulness in others.

Dolphins play to challenge themselves. Dolphin play is dynamic and becomes more complex with increasing age (Kuczaj et al., 2006; Kuczaj \& Horback, 2013; Kuczaj \& Makecha, 2008; Kuczaj \& Walker, 2012; McBride \& Hebb, 1948; Tavolga, 1966). Kuczaj et al. (2006) suggested that dolphins modify their play to keep it interesting and reinforcing. In one example they provided, a calf became proficient at blowing bubbles while swimming upside-down near the bottom of the pool and then chasing and biting each bubble before it reached the surface of the water. Once she was proficient at this, she modified her behavior by varying the number of bubbles released and the depth at which she released bubbles, her apparent goal being to catch the last bubble right before it reached the surface of the water. At one point, she began to release bubbles while swimming closer and closer to the surface, eventually being so close when she emitted bubbles that she could not catch a single bubble. Despite this failure, she persisted releasing bubbles near the surface until she had determined the absolute closest she could be to the surface and still catch and bite a bubble she produced. She also altered her swimming style while releasing bubbles, one variation involving a fast spin-swim. Producing bubbles during a swim-spin decreased her chances of biting all of the bubbles she released, but she practiced this behavior until she could catch most of the released bubbles. Thus, the dolphin controlled the difficulty of the game, striving to make it as difficult as possible yet still succeeding in biting all the bubbles she produced.

Observations of a dolphin calf at Dolphins Plus in Key Largo, Florida, yielded another example of play becoming more complex over time for an individual animal. Animals at this facility are housed in semi open ocean pens, which provide the dolphins with a variety of objects with which to play. Dolphin calves begin playing with grass, seaweed, algae and mangrove seedpods during the first month of life, typically by carrying the objects in their mouth. Detailed observations of one calf revealed that the young male began playing with mangrove seedpods, leaves and other fauna by placing them in his mouth or on the front of his rostrum. Around three months of age, he began to carry and balance the target objects on the front of his pectoral fins or dorsal fin. Approximately two months later, the calf began transferring the play object from one part of his body to another (e.g., from one pectoral fin to the other), as well as letting it slide down the ventral side of his body and then hitting it with his fluke. What began as simple exploratory play (mouthing objects) evolved into more complex forms of play is relatively short order.

Observations such as this led Kuczaj et al. (2006) to conclude that dolphins used play to create moderately discrepant events. Piaget (1952) proposed that the moderately discrepant events created by human children were essential aspects of their cognitive development because such events are both familiar and novel. The familiar aspect is important because it provides the child (or dolphin) a basis for interpreting the novel component of the situation, the successful interpretation of the novel aspect resulting in cognitive growth. This in turn provides a slightly more complex familiar basis to help interpret for a more complex event, a cycle that repeats itself throughout development to eventually yield a mature cognitive system.

Play provides a context in which dolphins are free to create their own moderately discrepant events, something they most likely do because challenging oneself is what keeps play interesting. Repeating the same behavior over and over again becomes boring, as does playing any sort of game that is too easy for one's abilities. Boredom is aversive and occurs when an organism is unable to engage in a satisfying activity (Eastwood, Frischen, Fenske, \& Smilek, 2012; Kuczaj et al., 2002), and challenging oneself during play enables that player to keep play satisfying. Kuczaj and Horback (2013) speculated that evolution may have selected for individuals that sought the challenges afforded by increasing the complexity of their play environments. As a result, even though dolphins do not intend this consequence, the creation of moderately discrepant events during play enhances cognitive development, including the ontogeny of flexible problem solving skills. Perhaps evolution has selected for individuals that seek the challenges provided by increasing the complexity of their play environments, as suggested by Kuczaj and Horback (2013). 


\section{The Significance of Play}

Play serves a variety of important functions, ranging from the simple pursuit of pleasure to the facilitation of cognitive skills (Burghardt, 2005). Play facilitates neuromuscular development, enhances motor skills, increases adaptability and flexibility both behaviorally and cognitively, and provides opportunities to practice and perfect social and communicative skills to be used in more serious affiliative and agnostic contexts (Bekoff, 2001; Bekoff \& Byers, 1981; Coelho \& Bramblett, 1982; Kuczaj \& Horback, 2013; Kuczaj et al., 2006; Thompson, 1996; West, 1974). The social significance of play rests at least in part on the experiences it provides for players to learn to produce appropriate emotional responses in a variety of contexts (Bekoff, 2002; Colvin \& Tissier, 1985; Fagen \& Fagen, 2004; Kuczaj \& Horback, 2013; Pellis \& Pellis, 2009; Singer \& Singer, 1990).

An important aspect of dolphin play concerns their predisposition to challenge themselves during play. Why do dolphins make their play more difficult? One reason is that challenging themselves during play keeps play interesting. Play provides a context in which dolphins can create their own moderately discrepant events, and so insure that their play remains stimulating. In turn, this may facilitate the ontogeny and maintenance of flexible problem solving skills. The presence of other playing animals is another driving force for increasingly complex play. Although the presence of other calves is not necessary for an individual calf's play to become more complex, the opportunity to interact with and observe other calves results in increasingly complex forms of play. This may occur because dolphin calves attempt to reproduce complex behaviors that older calves model and/or because calves strive to outdo one another (although there are undoubtedly individual differences in this regard), perhaps as they try to establish their social rank within the group. However, it is not only dolphin calves that challenge themselves during play. Adult dolphins also make their play more complex, and it is possible that dolphin play helps to maintain cognitive functioning throughout the life span.

Dolphin interest in the play of others may help us to understand the processes involved in the creation and maintenance of animal culture (Kuczaj et al., 2006). The transmission of cultural information necessitates some form(s) of social learning (Boyd \& Richerson, 1996; Rendell \& Whitehead, 2001) and so requires that an individual be able to learn via observation or teaching from another individual. Avital and Jablonka (2000) suggested that much of the information that constitutes animal culture is acquired during ontogeny. The existing data on dolphin play are consistent with this view, and highlight the role of peers in cultural transmission and innovation (Kuczaj et al., 2006). Dolphin calves appear to be key players in both the transmission and creation of the behaviors that comprise a group's culture, and the same may be true for the young of other social species. Additional research is needed to examine the relative roles of peers and adults in the acquisition of various forms of behaviors in a variety of species and contexts to determine the extent to which this hypothesis is true.

\section{Conclusions}

As we have seen, dolphins play for a variety of reasons. Dolphin calves play more than older dolphins, but adult dolphins also play. The functions and types of play in which dolphins engage change as dolphins mature. Locomotor play is more common in young dolphins than in adults. Such play facilitates muscular growth and coordination, and so is more important for growing animals that are learning about and testing the capacities of their bodies. Dolphin calves are also more likely to practice behaviors during play than are adults, a difference that once again reflects the greater need for young animals to perfect behaviors that will be used in foraging, mating, evading predators, and various forms of social interactions. Adult dolphins have learned these skills, and so have little need to practice them during play. Locomotor play by adult dolphins, although relatively rare compared to that of calves, may help adults maintain their physical strength, stamina, and flexibility.

Another developmental difference in dolphin play concerns the behavioral contagion of play. Young dolphins are very intrigued by the play of other dolphins, and are likely to either join in the play activity or closely observe it. Although some adult dolphins join in the play activities of others, adults are 
more likely to be unaffected by the play of others, the exception being when a novel object is involved. This developmental difference may reflect the fact that young dolphins are in general more interested in play than are adults. Or it might be due to adults having witnessed many types of play in their lives, decreasing the chances that they will find the play of others noteworthy. This possibility is supported by observations of adult dolphins attending to play that involves novel behaviors.

Dolphins of all ages challenge themselves during play, although this tendency appears to be more prevalent in young dolphins. Creating moderately discrepant events facilitates the growth of flexible problem solving skills, a crucial aspect of ontogeny for young dolphins. Adult dolphins that challenge themselves during play may be helping themselves maintain the critical cognitive skills that were acquired when they were young.

To sum up, play is an essential characteristic of dolphin life that serves a variety of functions. Both age and personality influence amounts and types of dolphin play. Additional work is needed to determine the manner in which individual differences affect the creativity of dolphin play, interest in the play of other dolphins, and curiosity about novel objects throughout the lifespan.

\section{References}

Addink, M. J., \& Smeenk, C. (2001). Opportunistic feeding behaviour of rough-toothed dolphins Steno bredanensis off Mauritania. Zoologische Verhandelingen, 29, 37-48.

Avital, E., \& Jablonka, E. (2000). Animal traditions: Behavioural inheritance in evolution. New York, NY: Cambridge University Press.

Bateson, G. (1955). A theory of play and fantasy. Psychiatric Research Reports, 2, 39-51.

Bateson, G. (1972). Steps to an ecology of mind. New York, NY: Ballantine Books.

Bekoff, M. (2001). Social play behaviour. Cooperation, fairness, trust, and the evolution of morality. Journal of Consciousness Studies, 8, 81-90.

Bekoff, M. (2002). Minding animals: Awareness, emotions, and heart. New York, NY: Oxford University Press.

Bekoff, M., \& Allen, C. (1998). Intentional communication and social play: How and why animals negotiate and agree to play. In M. Bekoff \& J. A. Byers (Eds.), Animal play: Evolutionary, comparative, and ecological perspectives (pp. 97-114). New York, NY: Cambridge University Press.

Bekoff, M., \& Byers, J. (1981). A critical reanalysis of the ontogeny of mammalian social and locomotor play: An ethological hornet's nest. In W. Barlow, K. Immelman, \& L. Petrinovich (Eds.), Behavioural development: The Bielefield interdisciplinary project (pp. 296-337). New York, NY: Cambridge University Press.

Bel'kovich, V. M., Ivanova, E. E., Kozarovitsky, L. B., Novikova, E. V., \& Kharitonov, S. P. (1991). Dolphin play behavior in the open sea. In K. Pryor \& K. S. Norris (Eds.), Dolphin societies: Discoveries and puzzles (pp. 67-77). Los Angeles, CA: University of California Press.

Bender, C. E., Herzing, D. L., \& Bjorklund, D. F. (2009). Evidence of teaching in Atlantic spotted dolphins (Stenella frontalis) by mother dolphins foraging in the presence of their calves. Animal Cognition, 12, 4353.

Berger, J. (1980). The ecology, structure and functions of social play in bighorn sheep (Ovis canadensis). Journal of Zoology, 192, 531-542.

Bjorklund, D. F., \& Pelligrini, A. D. (2010). Evolutionary perspectives on social development. In P. K. Smith \& C. H. Hart (Eds.), The Wiley-Blackwell handbook of childhood social development (pp. 64-81). Oxford, UK: Wiley-Blackwell.

Blomqvist, C., Mello, I., \& Amundin, M. (2005). An acoustic play-fight signal in bottlenose dolphins (Tursiops truncatus) in human care. Aquatic Mammals, 31, 187.

Boyd, R., \& Richerson, P. J. (1996). Why culture is common but cultural evolution is rare. Proceedings of the British Academy, 14, 113-118.

Buhler, C. (1935). From birth to maturity: An outline of the psychological development of the child. London, UK: Routledge \& Kegan Paul.

Burghardt, G. M. (2005). The genesis of animal play: Testing the limits. Cambridge, MA: MIT Press.

Buytendijk, F. J. J. (1933). Das Verhalten von Octopus Nach teilweiser Zerstorung des "Gehirns" [The behavior of Octopus after partial destruction (or removal) of its brain]. Archives Neerlandaises de Physiologie de l'Homme et des Animaux, 18, 24-70. 
Byers, J. A., \& Walker, C. (1995). Refining the motor training hypothesis for the evolution of play. American Naturalist, 146, 25-40.

Caro, T. M. (1995). Short-term costs and correlates of play in cheetahs. Animal Behaviour, 49, 333-345.

Chirigin, L. (1987). Mother-calf spatial relationships and calf development in the captive bottlenose dolphin (Tursiops truncatus). Aquatic Mammals, 13, 5-15.

Coelho, A. M., \& Bramblett, C. A. (1982). Social play in differentially reared infant and juvenile baboons (Papio sp). American Journal of Primatology, 3, 153-160.

Colvin, J. D., \& Tissler, G. (1985). Affiliation and reciprocity in sibling and peer relationships among free-ranging immature male rhesus monkeys. Animal Behaviour, 33, 959-977.

Connoly, J. A., \& Doyle, A. B. (1984). Relation of social fantasy play to social competence in preschoolers. Developmental Psychology, 20, 797-806.

Deakos, M. H., Branstetter, B. K., Mazzuca, L., Fertl, D., \& Mobley, J. R., Jr. (2010). Two unusual interactions between a bottlenose dolphin (Tursiops truncatus) and a humpback whale (Megaptera novaeangliae) in Hawaiian Waters. Aquatic Mammals, 36, 121-128.

Drea, C. M., Hawk, J. E., \& Glickman, S. E. (1996). Aggression decreases as play emerges in infant spotted hyenas: Preparation for joining the clan. Animal Behaviour, 51, 1323-1336.

Eastwood, J. D., Frischen, A., Fenske, M. J., \& Smilek, D. (2012). The unengaged mind defining boredom in terms of attention. Perspectives on Psychological Science, 7, 482-495.

Erikson, E. H. (1977). Toys and reasons: Stages in the ritualization of experience. New York, NY: Norton \& Company.

Fagen, R. (1981). Animal play behavior (pp. 102-112). New York, NY: Oxford University Press.

Fagen, R., \& Fagen, J. (2004). Juvenile survival and benefits of play behaviour in brown bears, Ursus arctos. Evolutionary Ecology Research, 6, 89-102.

Fripp, D., Owen, C., Quintana-Rizzo, E., Shapiro, A., Buckstaff, K., Jankowski, K., \& Tyack, P. (2005). Bottlenose dolphin (Tursiops truncatus) calves appear to model their signature whistles on the signature whistles of community members. Animal Cognition, 8, 17-26.

Gilmore, J. B. (1966). The role of anxiety and cognitive factors in children's play behavior. Child Development, 37, 397-416.

Gomendio, M. (1988). The development of different types of play in gazelles: Implications for the nature and functions of play. Animal Behaviour, 36, 825-836.

Gottman, J. M. (1986). The world of coordinated play: Same- and cross-sex friendship in children. New York, NY: Cambridge University Press.

Groos, K., \& Baldwin, E. L. (1898). The play of animals. New York, NY: D. Appleton and Company.

Highfill, L. E., \& Kuczaj, S. A., II (2007). Do bottlenose dolphins (Tursiops truncatus) have distinct and stable personalities? Aquatic Mammals, 33, 380-389.

Highfill, L. E., Kuczaj, S. A., II (2010). How studies of wild and captive dolphins contribute to our understanding of individual differences and personality. International Journal of Comparative Psychology, 23, 269-277.

Hill, H. M., Kuczaj, S. A., II, Greer, T., \& Solangi, M. (2007). All mothers are not the same: Maternal styles in bottlenose dolphins Tursiops truncates. International Journal of Comparative Psychology, 20, 35-54.

Holmes, B. J., \& Neil, D. T. (2012). Gift giving by wild bottlenose dolphins (Tursiops sp.) to humans at a wild dolphin provisioning program, Tangalooma, Australia. Anthrozoos: A Multidisciplinary Journal of The Interactions of People \& Animals, 25, 397-413.

Kano, F., \& Tomonaga, M. (2010). Face scanning in chimpanzees and humans: Continuity and discontinuity. Animal Behaviour, 79, 227-235.

Krützen, M., Mann, J., Heithaus, M. R., Connor, R. C., Bejder, L., \& Sherwin, W. B. (2005). Cultural transmission of tool use in bottlenose dolphins. Proceedings of the National Academy of Sciences of the United States of America, 102, 8939-8943.

Kuczaj, S. A., II (1982). Language play and language acquisition. In H. Reese (Ed.), Advances in child development and behavior (197-232). New York, NY: Academic Press.

Kuczaj, S. A., II (in press). Language learning in cetaceans. In P. Brooks, V. Kempe, \& J. Golsoon (Eds.), Encyclopedia of language development. Thousand Oaks, CA: Sage.

Kuczaj, S. A., II, (1983). Crib speech and language play. New York, NY: Springer-Verlag.

Kuczaj, S. A., II, \& Highfill, L. E. (2005). Dolphin play: Evidence for cooperation and culture? Behavioral and Brain Sciences, 28, 705-706. 
Kuczaj, S. A., II, Highfill, L., \& Byerly, H. (2012). The importance of considering context in the assessment of personality characteristics: Evidence from ratings of dolphin personality. International Journal of Comparative Psychology, 25, 309-329.

Kuczaj, S. A., II, Highfill, L. E., Makecha, R. N., \& Byerly, H. C. (2013). Why do dolphins smile? A comparative perspective on dolphin emotions and emotional expressions. In S. Watanabe \& S. A. Kuczaj II (Eds.), Comparative perspectives on human and animal emotions (pp. 63-86). Tokyo, Japan: Springer.

Kuczaj, S. A., II, \& Horback, K. M. (2013). Play and emotions. In S. Watanabe \& S. A. Kuczaj II (Eds.), Comparative perspectives on human and animal emotions (pp. 87-112), Tokyo, Japan: Springer.

Kuczaj, S. A., II, Lacinak, T., Fad, O., Trone, M., Solangi, M., \& Ramos, J. (2002). Keeping environmental enrichment enriching. International Journal of Comparative Psychology, 15, 127-137.

Kuczaj, S. A. II, \& Makecha, R. (2008). The role of play in the evolution and ontogeny of contextually flexible communication. In D. K. Oller \& U. Griebel (Eds.), Evolution of communicative flexibility: Complexity, creativity, and adaptability in human and animal communication (pp. 253-277). Cambridge, MA: The MIT Press.

Kuczaj, S. A., II, Makecha, R., Trone, M., Paulos, R. D., \& Ramos, J. A. (2006). Role of peers in cultural innovation and cultural transmission: Evidence from the play of dolphin calves. International Journal of Comparative Psychology, 19, 223-240.

Kuczaj, S. A., II, \& Walker, R. T. (2012). Dolphin problem solving. Handbook of comparative cognition (pp.736756). Oxford, UK: Oxford University Press.

Kuczaj, S. A., II, Yeater, D., \& Highfill, L. (2012). How selective is social learning in dolphins? International Journal of Comparative Psychology, 25, 221-236.

Lodi, L., \& Hetzel, B. (1999). Rough-toothed dolphin, Steno bredanensis, feeding behaviors in Ilha Grande Bay, Brazil. Biociências, 7, 29-42.

Lusseau, D. (2006). Why do dolphins jump? Interpreting the behavioural repertoire of bottlenose dolphins (Tursiops sp.) in Doubtful Sound, New Zealand. Behavioural Processes, 73, 257-265.

Mackey, A. D., Makecha, R. N., \& Kuczaj, S. A., II. (2014). The development of social play in bottlenose dolphins (Tursiops truncatus). Animal Behavior and Cognition, 1, 19-35.

Martin, P., \& Caro, T. M. (1985). On the functions of play and its role in behavioral development. Advances in the Study of Behavior, 15, 59-103.

McBride, A. F., \& Hebb, D. O. (1948). Behavior of the captive bottlenose dolphin, Tursiops truncatus. Journal of Comparative Physiological Psychology, 41, 111-123.

Miklósi, A. (1999). The ethological analysis of imitation. Biological Reviews, 74, 347-374.

Palagi, E. (2009). Adult play fighting and potential role of tail signals in ringtailed lemurs (Lemur catta). Journal of Comparative Psychology, 123, 1-9.

Paulos, R. D., Trone, M., \& Kuczaj, S. A., II (2010). Play in wild and captive cetaceans. International Journal of Comparative Psychology, 23, 701-722.

Pellegrini, A. D. (2011). The Oxford handbook of the development of play. New York, NY: Oxford University Press.

Pellis, S. M., \& Pellis, V. C. (1996). On knowing it's only play: The role of play signals in play fighting. Aggression and Violent Behavior, 1, 249-268.

Pellis, S. M., \& Pellis, V. C. (2007). Rough-and-tumble play and the development of the social brain. Current Directions in Psychological Science, 16, 95-98.

Pellis, S. M., \& Pellis, V. C. (2009). The playful brain. Venturing the limits of neuroscience. Oxford, UK: Oneworld Publications.

Pellis, S. M., \& Pellis, V. C. (2011). To whom the play signal is directed: A study of headshaking in black-handed spider monkeys (Ateles geoffroyi). Journal of Comparative Psychology, 125, 1-10.

Piaget, J. (1952). The origins of intelligence in children. New York, NY: Norton \& Company.

Piaget, J. (1962) Plays, dreams and imitation. New York, NY: Norton.

Power, T. G. (2000). Play and exploration in children and animals. Mahwah, NJ: Erlbaum.

Rendell, L., \& Whitehead, H. (2001). Culture in whales and dolphins. Behavioral and Brain Sciences, 24, 309-324.

Singer, D. G., \& Singer, J. L. (1990). The house of make-believe: Children's play and the developing imagination. Cambridge, MA: Harvard University Press.

Smeenk, C., Addink, C. M., \& Richards, H. (1995). Some observations of the behaviour of wild rough-toothed dolphins Steno bredanensis. Paper presented at the biennial meeting of the Society for Marine Mammalogy, Orlando, FL.

Sommer, V., \& Mendoza-Granados, D. (1995). Play as indicator of habitat quality: A field study of langur monkeys (Presbytis entellus). Ethology, 99, 177-192. 
Špinka, M., Newberry, R. C., \& Bekoff, M. (2001). Mammalian play: Training for the unexpected. Quarterly Review of Biology, 76, 141-168.

Sutton-Smith, B. (1980). Children's play: Some sources of play theorizing. New Directions for Child and Adolescent Development, 1980, 1-16.

Sutton-Smith, B. (2003). Play as a parody of emotional vulnerability. Play and Culture Studies, 5, 3-18.

Sutton-Smith, B. (2011). The antipathies of play. In A. D. Pellegrini, (Ed.). The Oxford handbook of the development of play. (pp, 110 -118). New York, NY: Oxford University Press.

Tavolga, M. C. (1966). Behavior of the bottlenose dolphin (Tursiops truncatus): Social interactions in a captive colony. In K. S. Norris (Ed.), Whales, dolphins, and porpoises (pp. 718-730). Berkeley and Los Angeles, CA: University of California Press.

Thompson, K. V. (1996). Play-partner preferences and the function of social play in infant sable antelope, Hippotragus niger. Animal Behaviour, 52, 1143-1155.

Trone, M., Kuczaj, S. A., II, \& Solangi, M. (2005). Does participation in dolphin-human interaction programs affect bottlenose dolphin behaviour? Applied Animal Behaviour Science, 93, 363-374.

van Baaren, R. B., Holland, R. W., Kawakami, K., \& Knippenberg, A. V. (2004). Mimicry and prosocial behavior. Psychological Science, 15, 71-74.

Vieira, M. L., \& Sartorio, R. (2002). Motivational, causal and functional analysis of play behavior in two rodent species. Estudos de Psicologia (Natal), 7, 189-196.

Vygotsky, L. S. (1978). Mind in society: The development of higher psychological processes. Cambridge, MA: Harvard University Press.

Weir, R. H. (1962). Language in the crib. London, UK: Mouton.

West, M. (1974). Social play in the domestic cat. American Zoologist, 14, 427-436.

Würsig, B., \& Würsig, M. (1979). Behavior and ecology of the bottlenose dolphin, Tursiops truncatus, in the south Atlantic. Fishery Bulletin, 77, 399-412.

Würsig, B., \& Würsig, M. (1980). Behavior and ecology of the dusky dolphin, Lagenorhynchus obscurus, in the South Atlantic. Fisheries Bulletin, 77, 871-890.

Yando, R., Seitz, V., \& Zigler, E. (1978). Imitation: A developmental perspective. Hillsdale, NJ: Erlbaum. 